\title{
Yarı Empedans Kaynaklı İnverter Devresinin Performans Analizi
}

\author{
Ramazan Akkaya ${ }^{1}$, Mustafa Sacid Endiz ${ }^{2 *}$ \\ ${ }^{1}$ Konya Teknik Üniversitesi, Mühendislik ve Doğa Bilimleri Fakültesi, Elektrik-Elektronik Mühendisliği Bölümü, Konya, Türkiye (ORCID: 0000-0002-4667-9456) \\ ${ }^{2}$ Necmettin Erbakan Üniversitesi, Mühendislik ve Mimarlık Fakültesi, Elektrik ve Elektronik Mühendisliği Bölümü, Konya, Türkiye (ORCID: 0000-0003-3325-5109)
}

( $1^{\text {st }}$ International Conference on Computer, Electrical and Electronic Sciences ICCEES 2020 - 8-10 Ekim 2020)

(DOI: $10.31590 /$ ejosat. 801852)

ATIF/REFERENCE: Akkaya, R. \& Endiz, M. S. (2020). Yarı Empedans Kaynaklı İnverter Devresinin Performans Analizi. Avrupa Bilim ve Teknoloji Dergisi, (Özel Sayı), 13-20.

\section{Öz}

Doğru akımı alternatif akıma dönüştürmek amacıyla güç elektroniği uygulamalarında yaygın olarak kullanılan akım ve gerilim kaynaklı inverterler üzerine günümüzde yeni topoloji çalışmaları yapılmaktadır. Geleneksel inverterlerin sahip olduğu kavramsal ve teorik sınırlamaları ortadan kaldırması empedans kaynaklı inverterleri (ZSI) son yıllarda oldukça popüler hale getirmiștir. ZSI inverterler; DC-DC dönüştürücü veya trafo kullanım ihtiyacı olmadan aynı faz kolunda bulunan yarı iletken anahtarlama elemanlarını kısa devre olarak sürebilmesi, uygulanan modülasyon indeksine bağlı olarak düşürücü veya yükseltici modunda çalışabilmesi ile esnek ve güvenilir devre yapısına sahip olması gibi birçok avantaja sahiptir. Bu çalışmada; yarı empedans kaynaklı inverter (qZSI) devresi için farklı çalışma koşulları altında performans analizi karşılaştırmalı olarak incelenmiştir. Anahtarlama elemanlarını kontrol etmek için en çok kullanılan kontrol yöntemlerinin başında gelen basit yükseltici kontrol tekniği belirli bir kazanç elde etmek amacıyla en yüksek gerilim stresine sahip olurken, maksimum yükseltici kontrol tekniği ise değişken süreli tetikleme sinyalleri üretmesi sonucunda empedans katında kullanılan elemanlar üzerinde istenmeyen düşük frekanslı dalgalanmalar oluşturmaktadır. Bu nedenle köprü katındaki anahtarlama elemanlarını sürebilmek için sabit yükseltici kontrol tekniği seçilmiştir. Düşük gerilim stresi ve değişken olmayan kısa devre çalışma oranına sahip sabit yükseltici kontrol tekniğinin çalışma prensibi açıklanmıştır. qZSI devresinin farklı modülasyon indeksleri ve DC giriş gerilim değerlerinde yükseltme faktörü, gerilim kazancı, gerilim stresi ve AC çıkış gerilimleri, ilgili denklemler kullanılarak hesaplanmıştır. Matlab/Simulink programı kullanılarak yapılan benzetim çalışmaları ile teorik sonuçlar doğrulanmıştır. Elde edilen bulgulara göre uygulanan kontrol tekniği ile kararlı kısa devre görev süreleri üretilmiş ve qZSI dönüştürücü devresi farklı çalışma durumlarında istenilen çıkış gerilimini üretmek için düşürücü-yükseltici olarak çalışabilmiştir.

Anahtar Kelimeler: Empedans kaynaklı inverter, Yükseltme faktörü, Gerilim kazancı, Gerilim stresi, Sabit yükseltici kontrol.

\section{Performance Analysis of a Quasi-Z-Source Inverter Circuit}

\begin{abstract}
Today, new topology studies have been introduced for current and voltage source inverters that are widely used in power electronics applications in order to convert direct current to alternating current. In recent years, Z-source inverters (ZSIs) have become very popular by eliminating the conceptual and theoretical limitations of traditional inverters. ZSIs have the advantages like the shootthrough operation in the same phase leg of the inverter without using of DC-DC converters or transformers, the ability to operate as a buck or boost inverter depending on the applied modulation index and having a flexible-reliable circuit structure. In this study, performance analysis of a quasi Z-source inverter circuit (qZSI) under different operation conditions is comparatively examined. Among the most used control methods for the switching devices, the simple boost control technique has the largest voltage stress for a given voltage gain and the maximum boost control technique produces variable shoot-through signals resulting of low-frequency ripples on the passive components in the impedance network. Therefore constant boost control technique has been applied to the
\end{abstract}

\footnotetext{
*Necmettin Erbakan Üniversitesi, Mühendislik ve Mimarlık Fakültesi, Elektrik ve Elektronik Mühendisliği Bölümü, Konya, Türkiye ORCID: 00000003-3325-5109, msendiz@erbakan.edu.tr
} 
switches to generate the gate signals. The operating principle of the constant boost control technique with low voltage stress and stable shoot-through signals is explained. Boost factor, voltage gain, voltage stress and AC output voltage for different modulation indexes and DC voltage values of the qZSI are calculated with the related equations. Theoretical results have been verified with simulation studies by using Matlab/Simulink environment. According to the findings, stable shoot-through duty ratios are generated, and the qZSI circuit has been able to operate as a buck-boost converter to obtain the desired output voltage for different cases.

Keywords: Impedance source inverter, Boost factor, Voltage gain, Voltage stress, Constant boost control.

\section{Giriş}

Rüzgâr ve güneş enerjisi gibi yenilenebilir enerji kaynaklarının yaygın olarak kullanılmasıyla birlikte DC-AC dönüştürücüler endüstriyel alanda oldukça fazla önem kazanmıştır [Endiz ve ark. 2015]. Özellikle fotovoltaik sistemlerden üretilen DC gerilim değeri gün içerisinde sıcaklık ve 1şıma değerlerine bağlı olarak sürekli değişmektedir. Bu durum kullanılan dönüştürücünün çok geniş bir gerilim aralığında çalışmasını zorunlu kılar. Geleneksel gerilim kaynaklı inverterler, sadece belirli bir gerilim aralığında ve yapıları itibariyle düşürücü modda çalışabildeklerinden transformatör veya yükseltici DC-DC dönüştürücü ile beraber kullanılmaktadır [Kabalc1, 2020].

Gerilim kaynaklı inverterlerin neden olduğu teorik kısıtlamaların üstesinden gelebilmeleri, maliyetlerinin düşük, devre yapılarının esnek oluşu ile tek aşamada hem yükseltme hem de dönüştürme yapabilmeleri; empedans kaynaklı inverterleri (ZSI) günümüzde en çok tercih edilen DC-AC dönüştürücü yapısı haline getirmiştir [Peng, 2003].

Son yıllarda ZSI devresine alternatif olarak yarı empedans kaynaklı inverter (qZSI) devresi ortaya konulmuştur [Anderson ve ark, 2008]. ZSI’ye kıyasla qZSI devresinin DC kaynaktan sürekli halde akım çekebilmesi, çok geniş bir gerilim aralığında çalışabilmesine imkân sağladığı için fotovoltaik sistemlerde kullanımını avantajlı hale getirmiştir. Ayrıca qZSI inverterler, empedans katında daha düşük nominal değerli elemanlara ve daha az gerilim stresine sahiptir [Liu ve ark. 2011].

$\mathrm{Bu}$ çalışmada, fotovoltaik bir sistemde kullanılan qZSI inverter devresinin farklı modülasyon indeksleri ve DC gerilim değerlerinde yükseltme faktörü, gerilim kazancı, gerilim stresi ve AC çıkış gerilim değerleri için çalışma performansı Matlab/Simulink ortamında benzetimi yapılarak incelenmiştir. Öncelikle qZSI inverter devresinin çalışma prensibi ve teorik analizi yapılmış, daha sonra devrenin hem düşürücü hem de yükseltici olarak çalışması benzetim çalışmaları yardımıyla gösterilmiştir.

\section{Materyal ve Metot}

Akademik çalışmalar ile mühendislik uygulamalarında oldukça yaygın olarak kullanılan Matlab/Simulink programı, araştırmacılara tasarım esnekliği ve birçok durumda değişen parametre değerlerini kolayca uygulama imkânı vermektedir. Bu çalışmada qZSI inverter devresinin farklı çalışma koşulları altında performans analizi Matlab/Simulink programı kullanılarak yapilmıştır.

\section{1. qZSI Devresinin Teorik Analizi}

qZSI inverterin devre analizi yapıldığında, ZSI inverterde kullanılan tüm kabullerin qZSI inverter devresi için geçerli olduğu görülür. Belirtildiği üzere topolojiler arasında iki temel fark vardır. Bunlar; qZSI inverter devresinin girişinde bulunan bobin yardımıyla DC güç kaynağından sürekli ve sabit akım çekebilme özelliği ile empedans katında daha düşük nominal değerli pasif bileşenlere sahip olmasıdır [Anderson ve ark. 2008]. qZSI inverter devresi, empedans kaynağındaki pasif devre elemanlarının şarjdeşarj olma özelliğini kullanarak kısa devre çalışma neticesinde istenilen seviyede gerilim yükseltmesi sağlar [Elabban ve Abu-Rub, 2016; Endiz ve Akkaya, 2020].

Şekil 1'de qZSI temel devre şeması, Şekil 2 ve Şekil 3'de sırasıyla qZSI devresinin aktif ve sıfır çalışma durumlarının oluşturduğu kısa devre olmayan çalışma modu ve kısa devre çalışma modu eşdeğer devre şemaları gösterilmiştir.

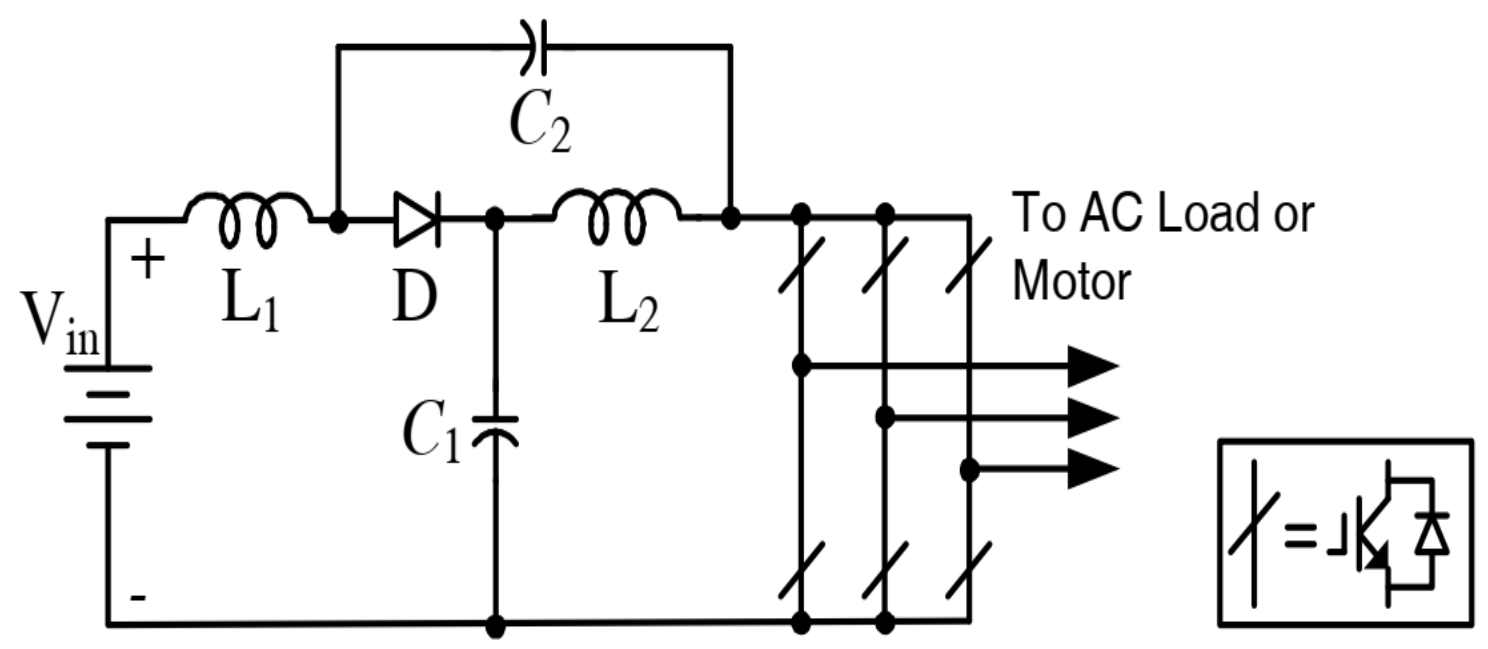

Şekil 1. qZSI temel devre şeması 


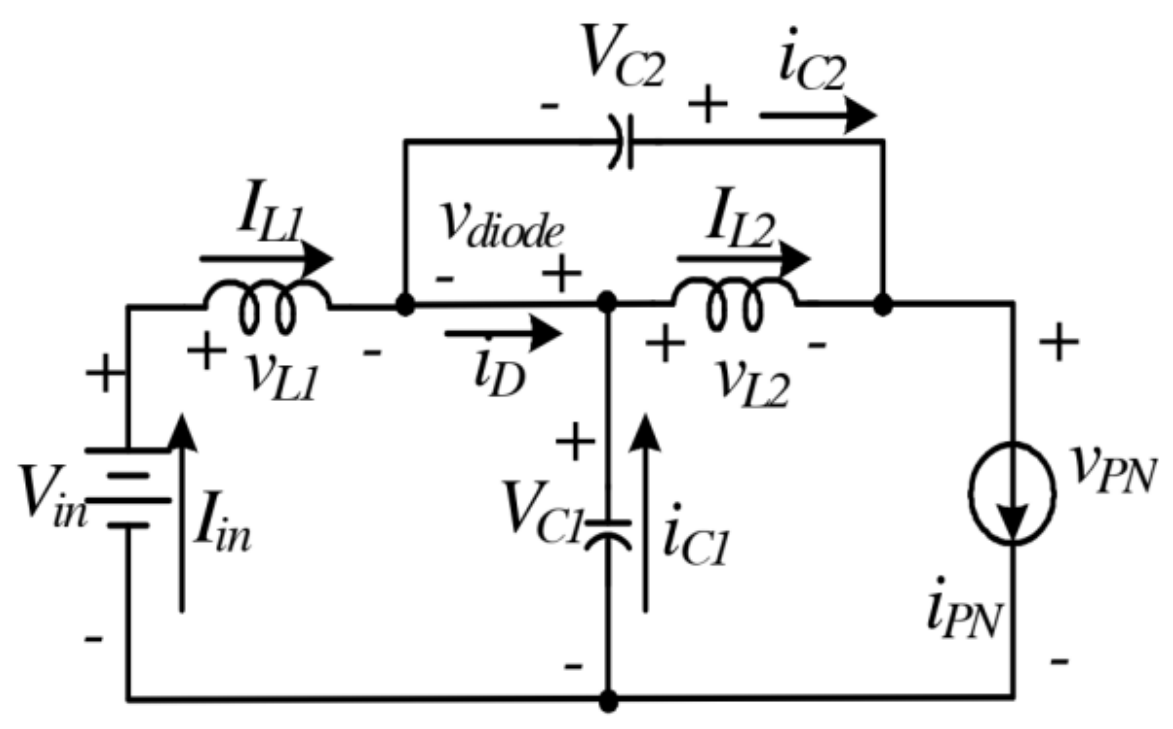

Şekil 2. qZSI kısa devre olmayan eşdeğer devre şeması

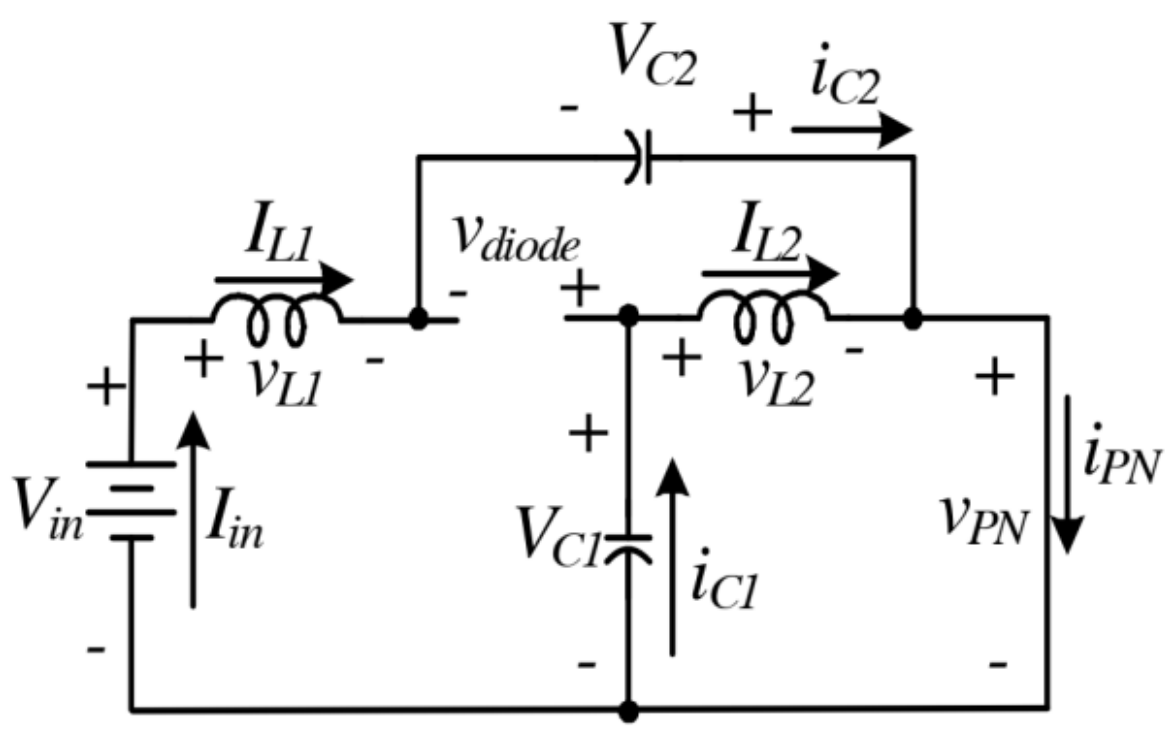

Şekil 3. qZSI kısa devre eşdeğer devre şeması

Şekil 2'de qZSI inverter devresinin kısa devre olmayan çalışma modunda gerilim polaritesi ve akım yönleri gösterilmiştir. $\mathrm{T}_{0}$ ve $\mathrm{T}_{1}$ 'in $\mathrm{T}$ periyodu süresince sırasıyla kısa devre çalışma süresi ve aktif çalışma süresi olduğu kabul edilirse; $\mathrm{D}$ görev süresi oranı $\mathrm{T}_{0}$ süresinin $T_{1}$ süresine oranına eşittir. Şekil 1'deki qZSI inverter devresinde; $T_{1}$ aktif çalışma süresince $V_{L_{1}}$ ve $V_{L_{2}}$ bobin gerilimlerini, $\mathrm{I}_{\mathrm{L} 1}$ ve $\mathrm{I}_{\mathrm{L} 2}$ bobin akımlarını, $\mathrm{V}_{\mathrm{C} 1}$ ve $\mathrm{V}_{\mathrm{C} 2}$ kondansatör gerilimlerini, $\mathrm{I}_{\mathrm{C} 1}$ ve $\mathrm{I}_{\mathrm{C} 2}$ kondansatör akımların1, $\mathrm{V}_{\text {in }}$ ve $\mathrm{I}_{\text {in }} \mathrm{DC}$ kaynak gerilim ve akımlarını, $\mathrm{V}_{\mathrm{PN}}$ DC hat gerilimini, $\mathrm{V}_{\text {diode }}$ diyot gerilimini ve B yükseltme faktörünü göstermektedir.

$\mathrm{V}_{\mathrm{L} 1}$ ve $\mathrm{V}_{\mathrm{L} 2}$ bobin gerilimleri eşitlik (1)'de gösterilmiştir. $\mathrm{T}_{1}$ aktif çalışma süresi boyunca $\mathrm{V}_{\mathrm{PN}}$ DC hat gerilimi ve $\mathrm{V}_{\text {diode }}$ diyot gerilimi eşitlik (2) kullanılarak hesaplanır.

$$
\begin{aligned}
& V_{L 1}=V_{\text {in }}-V_{C 1} \text { ve } V_{L 2}=-V_{C 2} \\
& V_{P N}=V_{C 1}+V_{C 2} \text { ve } V_{\text {diode }}=0
\end{aligned}
$$

Şekil 3 'te qZSI inverter devresi kısa devre çalışma modunda gerilim polaritesi ve akım yönleri $\mathrm{T}_{0}$ kısa devre çalışma süresince gösterilmiştir. $\mathrm{V}_{\mathrm{L} 1}$ ve $\mathrm{V}_{\mathrm{L} 2}$ bobin gerilimleri eşitlik (3) kullanılarak hesaplanır.

$$
\begin{aligned}
& V_{L 1}=V_{\text {in }}+V_{C 2} \text { ve } V_{L 2}=V_{C 1} \\
& V_{P N}=0 \text { ve } V_{\text {diode }}=V_{C 1}+V_{C 2}
\end{aligned}
$$

Sürekli durum analizinde $\mathrm{T}$ periyot süresi boyunca bobinin ortalama gerilim değerinin sıfir olacağı kabul edilmektedir. qZSI inverter devresinde $V_{C 1}$ ve $V_{C 2}$ kondansatör gerilimleri eşitlik (7) kullanılarak hesaplanır.

$$
V_{L 1}=\frac{\left[T_{0}\left(V_{i n}+V_{C 2}\right)+T_{1}\left(V_{i n}-V_{C 1}\right)\right]}{T}=0
$$




$$
\begin{aligned}
& V_{L 2}=\frac{\left[T_{0} V_{C 1}+T_{1}\left(-V_{C 2}\right)\right]}{T}=0 \\
& V_{C 1}=\frac{T_{1}}{T_{1}-T_{0}} * V_{\text {in }} \text { ve } V_{C 2}=\frac{T_{0}}{T_{1}-T_{0}} * V_{\text {in }}
\end{aligned}
$$

Eşitlik (8) kullanılarak qZSI inverter devresinde DC hat gerilimi tepe değeri $\mathrm{V}_{\mathrm{PN}}$ bulunur.

$$
V_{P N}=V_{C 1}+V_{C 2}=\frac{T}{T_{1}-T_{0}} * V_{\text {in }}=B * V_{\text {in }}
$$

Sistemin gücünün P olduğu kabul edilip $\mathrm{I}_{\mathrm{L} 1}$ ve $\mathrm{I}_{\mathrm{L} 2}$ bobin akımları eşitlik (9) kullanılarak, $\mathrm{I}_{\mathrm{C} 1}$ ve $\mathrm{I}_{\mathrm{C} 2}$ kondansatör akımlar1 Kirchhoff akım kanunları yardımıyla eşitlik (10) kullanılarak hesaplanır.

$$
\begin{gathered}
I_{L 1}=I_{L 2}=I_{\text {in }}=\frac{P}{V_{\text {in }}} \\
I_{C 1}=I_{C 2}=I_{P N}-I_{L 1}
\end{gathered}
$$

\section{2. qZSI Devresi Kontrol Yöntemi}

qZSI inverterlerde kullanılan taşıyıcı tabanlı (DGM) kontrol teknikleri sırasıyla; basit yükseltici kontrol (BYK), maksimum yükseltici kontrol (MYK) ve maksimum sabit yükseltici kontrol (MSYK) teknikleridir [Shen ve ark. 2004; Peng ve ark. 2005]. BYK yönteminin belirli bir kazançta en yüksek gerilim stresine sahip olması ve MYK yönteminin değişken süreli kısa devre sinyallerinin empedans katındaki pasif elemanlar üzerinde düşük frekanslı dalgalanmalar oluştuması bu iki kontrol tekniğini dezavantajlı hale getirmiştir [Liu ve ark. 2014, Endiz ve Akkaya, 2019]. Bu nedenle 3. harmonik ilaveli MSYK kontrol yöntemi bu çalışmada kullanılmıştır. İnverter devrelerinde DC bara kullanım oranı ile modülasyon indeks aralığını arttırması amacıyla 3. harmonik eklenmesi tekniği sıklıkla uygulanmaktadır [Battiston ve ark. 2016; Endiz ve Akkaya, 2020]. 3. harmonik ilaveli MSYK yönteminde kullanılan kontrol sinyalleri ile üretilen anahtarlama sinyalleri sırasıyla Şekil 4 ve Şekil 5 'te gösterilmiştir. Şekil 4 'te görülen kontrol sinyallerinde üçgen dalga düz kısa devre sinyallerinden genlik olarak büyük olması durumunda qZSI inverter devresi kısa devre moduna geçecektir. Bunun dişındaki durumlarda devre geleneksel DGM kontrollü inverter devresi gibi çalışacaktır [Subhani ve ark. 2019; Yu ve Sajadian, 2020]. Şekil 5’te görüldüğü üzere üretilen kısa devre sinyalleri sabit ve kararlıdır. MSYK yönteminde kullanılan yükseltme oranı B ile gerilim kazancı G ifadeleri (11) ve (12) eşitliklerinde verilmiştir.

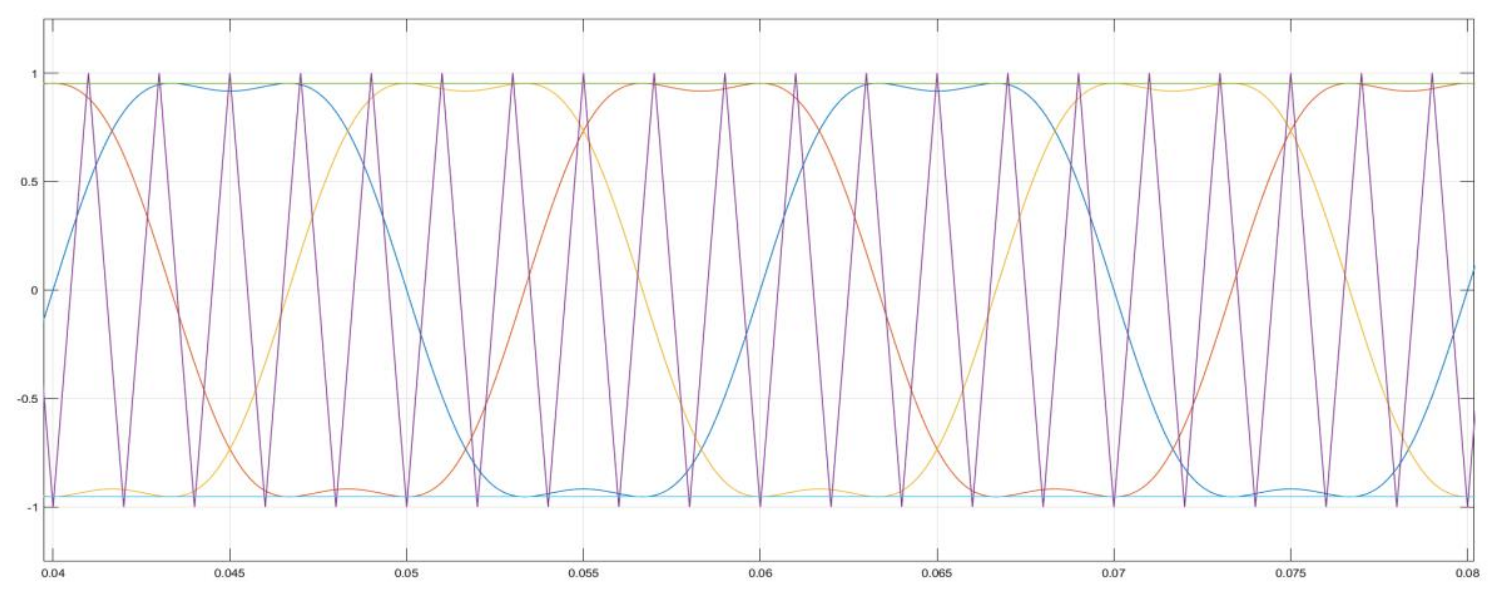

Şekil 4. 3. harmonik ilaveli MSYK kontrol sinyalleri
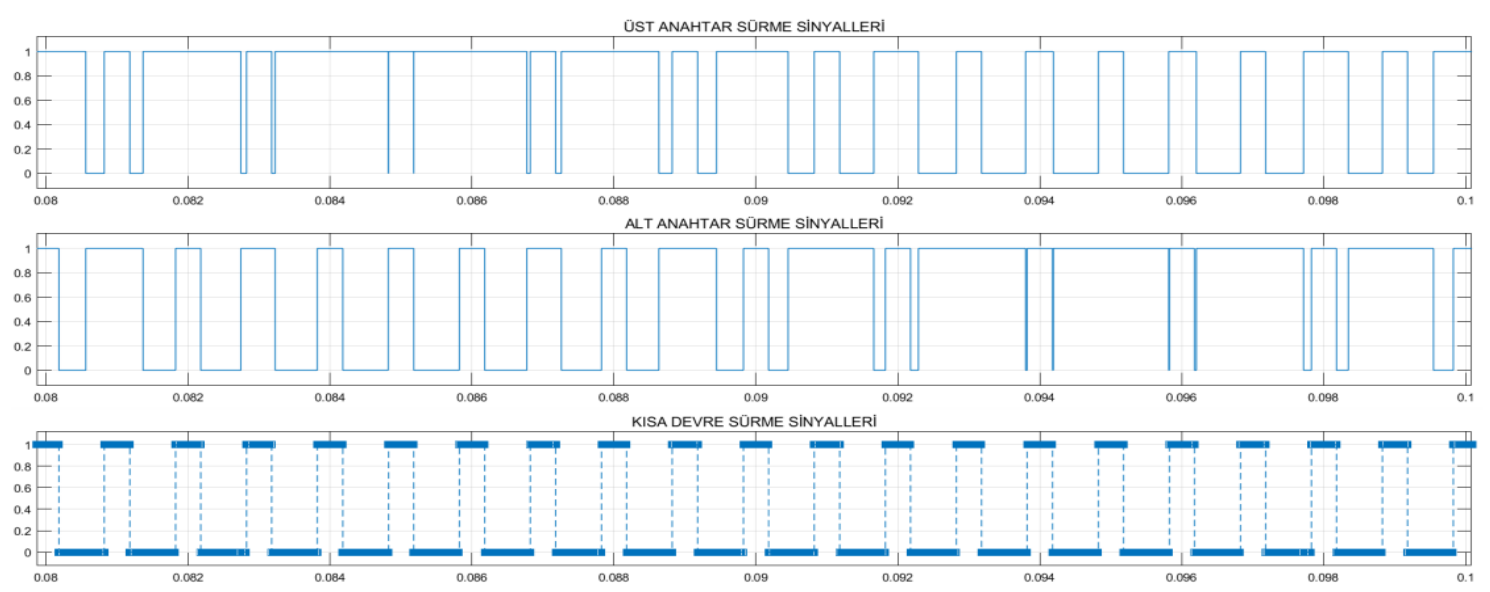

Şekil 5. MSYK kontrollü üretilen anahtarlama sinyalleri 


$$
\begin{aligned}
& B=\frac{1}{\sqrt{3} \mathrm{M}-1} \\
& \mathrm{G}=\frac{M}{\sqrt{3} \mathrm{M}-1}
\end{aligned}
$$

Şekil 2'de gösterildiği gibi qZSI devresi sadece kısa devre olmayan modda çalıştırılmak istenirse, diyot iletimde, $\mathrm{C}_{1}$ kondansatörü ve $V_{P N} D C$ hat gerilimi giriş gerilim değerine, $C_{2}$ kondansatörü ise sıfıra eşit olacaktır. Kısa devre çalışma olmadığı için $D=0$ ve $B=1$ olup devre düşürücü modda geleneksel gerilim kaynaklı inverter gibi olacaktır. Bu durumda çıkış gerilimi tepe değeri $\tilde{V}_{\mathrm{AN}}$ eşitlik (13)'teki gibi hesaplanır.

$$
\tilde{\mathrm{V}}_{A N}=M * \frac{\tilde{\mathrm{V}}_{P N}}{2}=M * \frac{\tilde{\mathrm{V}}_{D C}}{2}
$$

Şekil 3'te verildiği şekilde qZSI inverter devresi kısa devre çalışma moduna geçtiğinde $\mathrm{D}>0$ ve B $>1$ olup devre yükseltici modda çalışacaktır. Çıkış gerilimi tepe değeri $\tilde{V}_{\text {AN }}$ eşitlik (14)’teki gibi hesapanır. Eşitlik (13) ve (14) karşılaştırıldığında ilk durumda devrenin düşürücü, ikinci durumda ise yükseltici moduna geçtiği görülmektedir.

$$
\tilde{\mathrm{V}}_{A N}=M * B * \frac{\tilde{\mathrm{V}}_{P N}}{2}=M * B * \frac{\tilde{\mathrm{V}}_{D C}}{2}
$$

\section{Araştırma Sonuçları ve Tartışma}

Yapılan benzetim çalışmalarında farklı çalışma durumlar için üç fazlı bir fotovoltaik sistemin $220 \mathrm{~V}-50 \mathrm{~Hz}$ üretebilmesi amaçlanmaktadır. Devrenin empedans katında kullanılan pasif elemanlar $\mathrm{C}_{1}=\mathrm{C}_{2}=470 \mathrm{uF}, \mathrm{L}_{1}=\mathrm{L}_{2}=500 \mathrm{uH}$ ve filtre elemanları $\mathrm{L}_{\mathrm{F}}=1 \mathrm{mH}$ ile $\mathrm{C}_{\mathrm{F}}=100 \mathrm{uF}$ ve yük değeri faz başına $\mathrm{R}_{\mathrm{L}}=10 \Omega$ olarak seçilmiştir. Sistemin giriş gerilim değeri çevre şartlarına bağlı olarak $300 \mathrm{~V}$ $600 \mathrm{~V}$ arasında değiștiği kabul edilerek 3 farklı durum için benzetimleri yapılmıştır. Devrenin düşürücü veya yükseltici olarak çalışması eşitlik (13) ve (14)'te verilen denklemlere göre belirlenir. Şekil 6-11'de sirasıyla düşürücü ve yükseltici modda $\mathrm{V}_{\mathrm{PN}}$, $\mathrm{V}_{\mathrm{C}}$, $\mathrm{V}_{\mathrm{DC}}$ ve $\mathrm{V}_{\mathrm{AC}}$ gerilimleri gösterilmiştir. Düşürücü modda çalışılabilecek en düşük gerilim 3. harmonik ilaveli $\mathrm{M}=1.15$ değeri için eşitlik (13)'e göre $\mathrm{V}_{\mathrm{DC}}=539 \mathrm{~V}$ bulunur. Sistemin giriş gerilim değeri bu değerin altına düşerse yükseltici modda, bu değerin üzerinde olduğunda düşürücü modda çalışacaktır. Yükseltici modda çalışması durumunda maksimum kazanç ifadesi giriş geriliminin en küçük değeri $\mathrm{V}_{\mathrm{DC}}=300 \mathrm{~V}$ için $\mathrm{G}_{\max }=1.95$ olarak bulunur. Kullanılan MSYK yöntemine bağlı olarak yükseltici durumda olabilecek en düşük modülasyon indeksi $\mathrm{M}_{\min }$ ve en büyük yükseltme faktörü $\mathrm{B}_{\max }$ eşitlik (15) ve (16)'da verilen denklemlere göre hesaplanır.

$$
\begin{aligned}
& M_{\text {min }}=\frac{G_{\text {max }}}{\sqrt{3} G_{\text {max }}-1}=0.82 \\
& B_{\text {max }}=\frac{1}{\sqrt{3} M_{\text {min }}-1}=2.35
\end{aligned}
$$

İlk durum senaryosu $\mathrm{M}=0.82$ ve $\mathrm{V}_{\mathrm{DC}}=600 \mathrm{~V}$ olarak ayarlanmıştır. Giriş gerilim değeri 539V'tan büyük olduğu için qZSI inverter devresi düşürücü modda yani geleneksel DGM kontrollü bir inverter gibi çalışacaktır. Kısa devre çalışma durumu olmayacağından $\mathrm{D}=0, \mathrm{~B}=1$ ve $\mathrm{G}=1$ olarak bulunur. Çıkış faz gerilimi tepe değeri $\tilde{\mathrm{V}}_{\mathrm{AN}}=300 \mathrm{~V}, \mathrm{C}_{1}$ kondansatörü DC kaynak gerilim değerine eşit olup $600 \mathrm{~V}$ ve $\mathrm{C}_{2}$ kondansatörü $0 \mathrm{~V}$ bulunur.

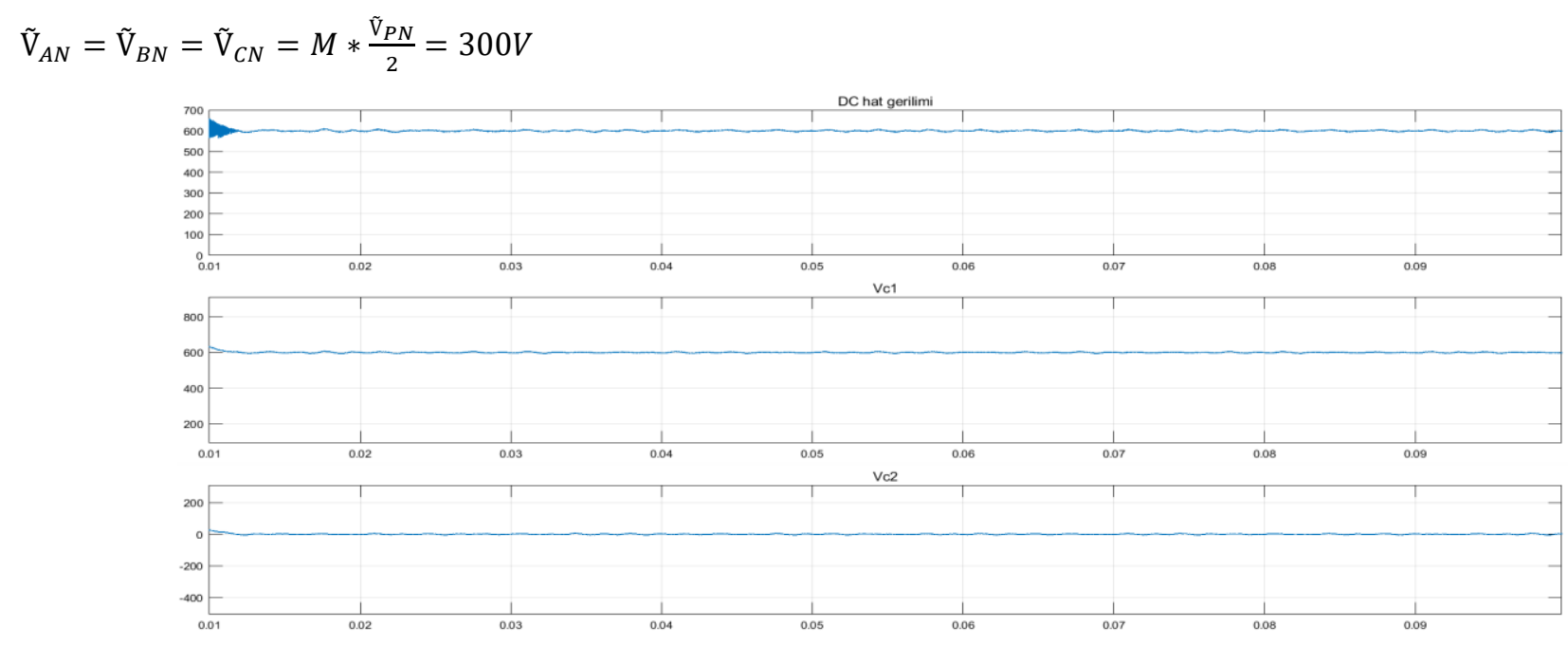

Şekil 6. Düşürücü modda $\mathrm{V}_{\mathrm{PN}}$ ve $\mathrm{V}_{\mathrm{C}}$ gerilimleri ( $\left.\mathrm{M}=0.82\right)$ 

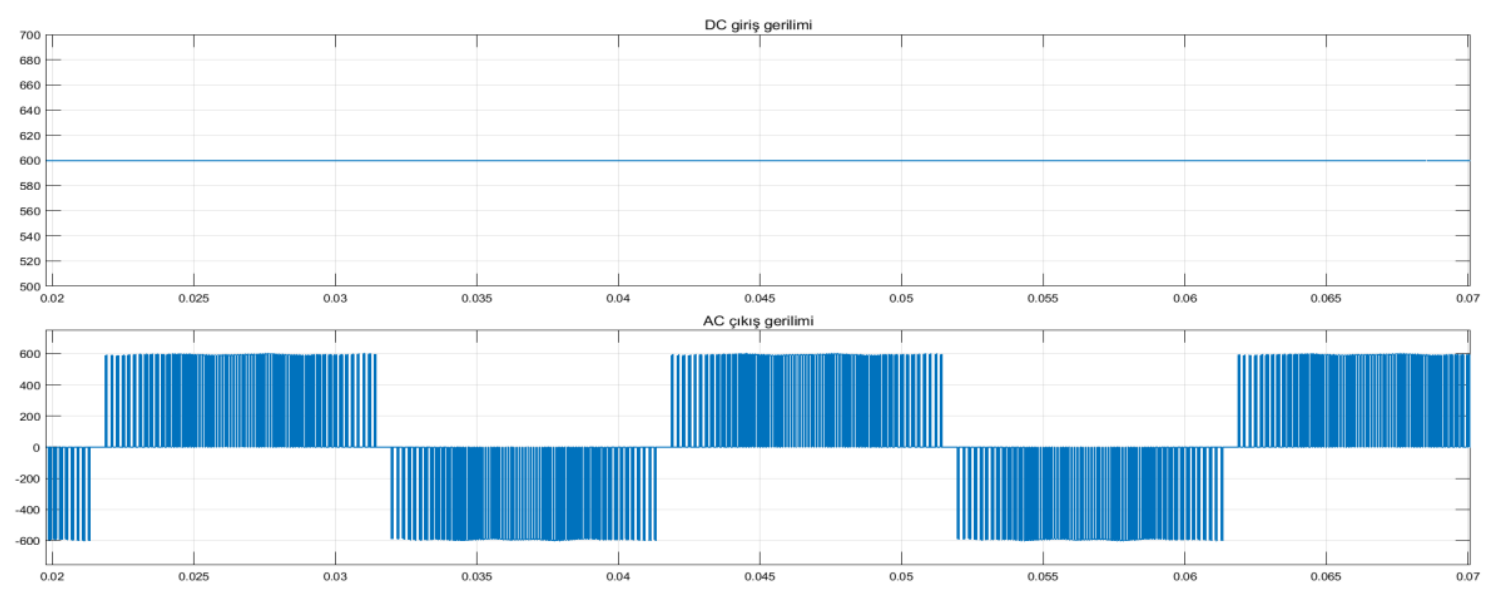

Şekil 7. Düşürücü modda $V_{D C}$ ve $V_{A C}$ gerilimleri $(M=0.82)$

İkinci durum senaryosu $\mathrm{M}=1$ ve $\mathrm{V}_{\mathrm{DC}}=450 \mathrm{~V}$ olarak ayarlanmıştır. $\mathrm{DC}$ gerilim değeri $539 \mathrm{~V}$ 'tan küçük olduğu için qZSI inverter devresi yükseltici modda çalıştııılmalıdır. Kısa devre çalışma söz konusu olduğundan eşitlik (11) ve (12)'de verilen denklemlere göre $\mathrm{B}=1.37$ ve $\mathrm{G}=\mathrm{M} * \mathrm{~B}=1.37$ olarak hesaplanır. $\mathrm{DC}$ hat gerilim değeri $\mathrm{V}_{\mathrm{PN}}=612 \mathrm{~V}$ 'a yükseltilirken çıkış faz gerilimi tepe değeri $\tilde{\mathrm{V}}_{\mathrm{AN}}=305 \mathrm{~V}, \mathrm{C}_{1}$ ve $\mathrm{C}_{2}$ kondansatörleri sirasiyla $470 \mathrm{~V}$ ve $145 \mathrm{~V}$ olur.

$$
\tilde{V}_{A N}=\tilde{V}_{B N}=\tilde{V}_{C N}=M * B * \frac{\tilde{V}_{P N}}{2}=305 V
$$
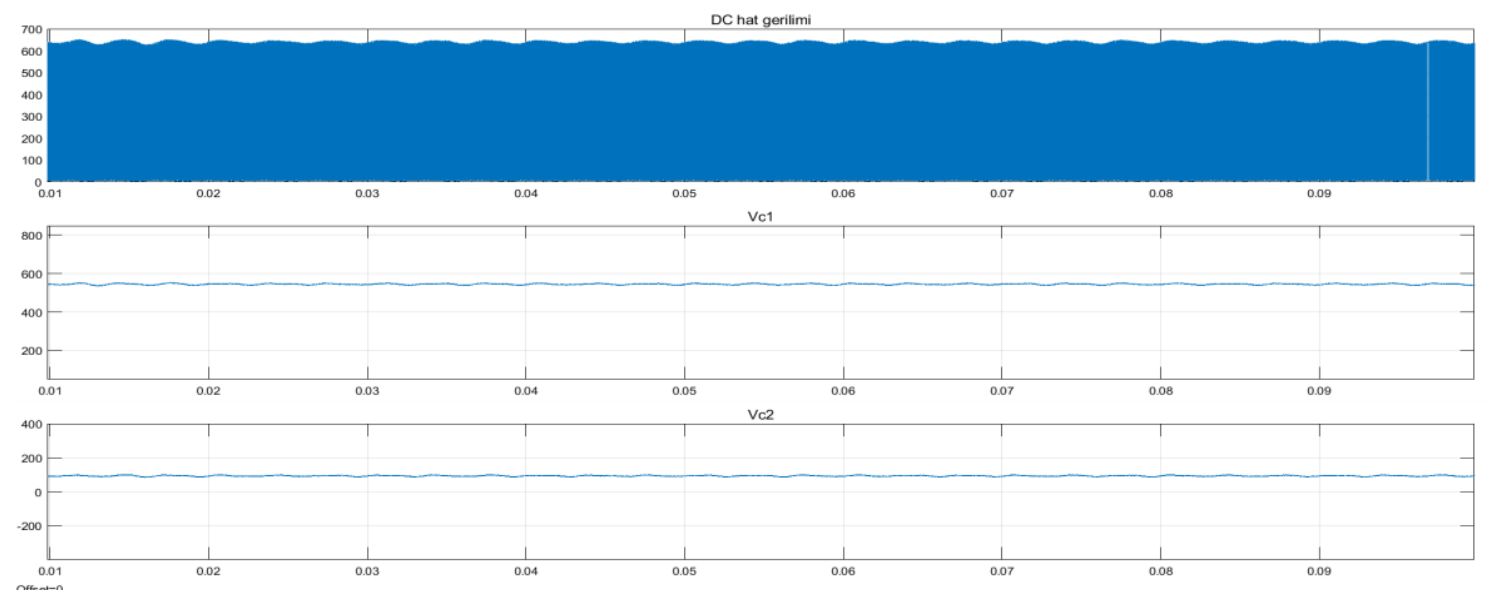

Şekil 8. Yükseltici modda $\mathrm{V}_{\mathrm{PN}}$ ve $\mathrm{V}_{\mathrm{C}}$ gerilimleri $(\mathrm{M}=1)$
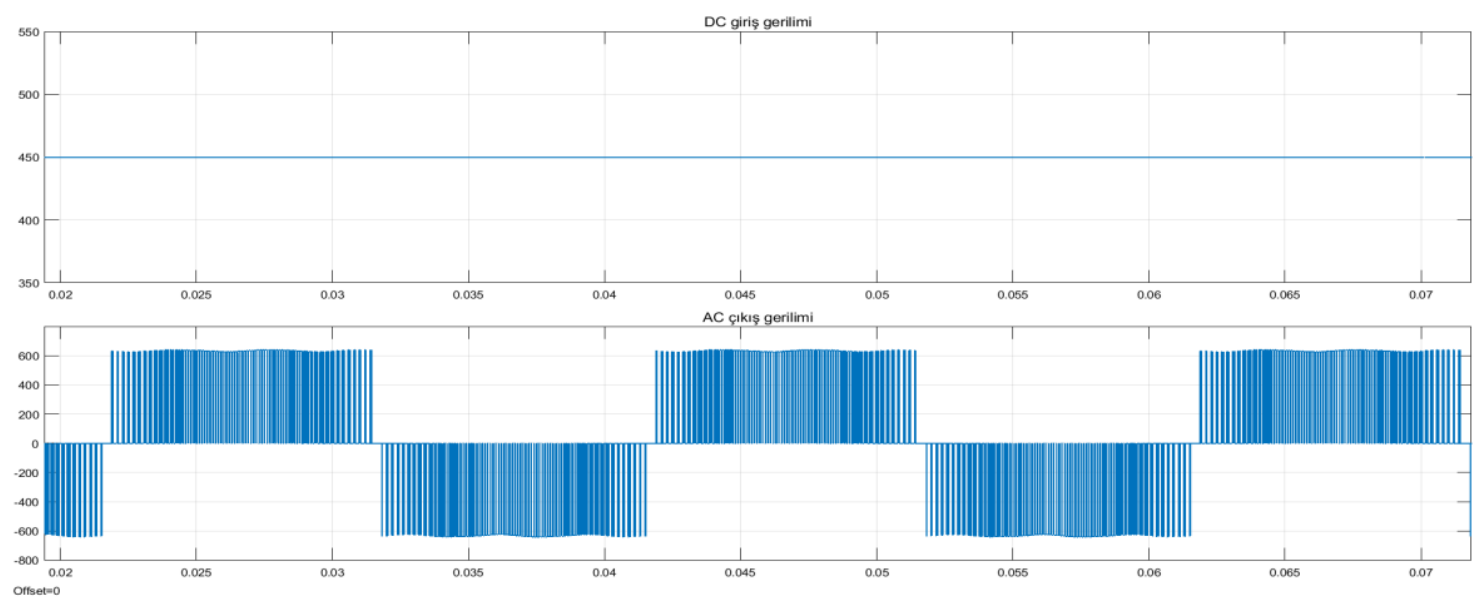

Şekil 9. Yükseltici modda $V_{D C}$ ve $V_{A C}$ gerilimleri $(M=1)$

Üçüncü durum senaryosu $\mathrm{M}=0.82$ ve $\mathrm{V}_{\mathrm{DC}}=300 \mathrm{~V}$ olarak ayarlanmıştır. Giriş gerilim değeri 539V'un altında olmasından dolayı qZSI devresi yükseltici modda çalışacaktır. Benzer şekilde eşitlik (11) ve (12) kullanılarak $\mathrm{B}=2.35$ ve $\mathrm{G}=\mathrm{M} * \mathrm{~B}=1.95$ olarak hesaplanır. $\mathrm{DC}$ hat gerilim değeri $\mathrm{V}_{\mathrm{PN}}=675 \mathrm{~V}$ 'a yükselirken çıkış faz gerilimi tepe değeri $\tilde{\mathrm{V}}_{\mathrm{AN}}=300 \mathrm{~V}$, sirasıyla $\mathrm{C}_{1}$ ve $\mathrm{C}_{2}$ kondansatörleri üzerine düşen gerilim değerleri $480 \mathrm{~V}$ ve $195 \mathrm{~V}$ olur. 


$$
\tilde{\mathrm{V}}_{A N}=\tilde{\mathrm{V}}_{B N}=\tilde{\mathrm{V}}_{C N}=M * \frac{\tilde{\mathrm{V}}_{P N}}{2}=300 \mathrm{~V}
$$
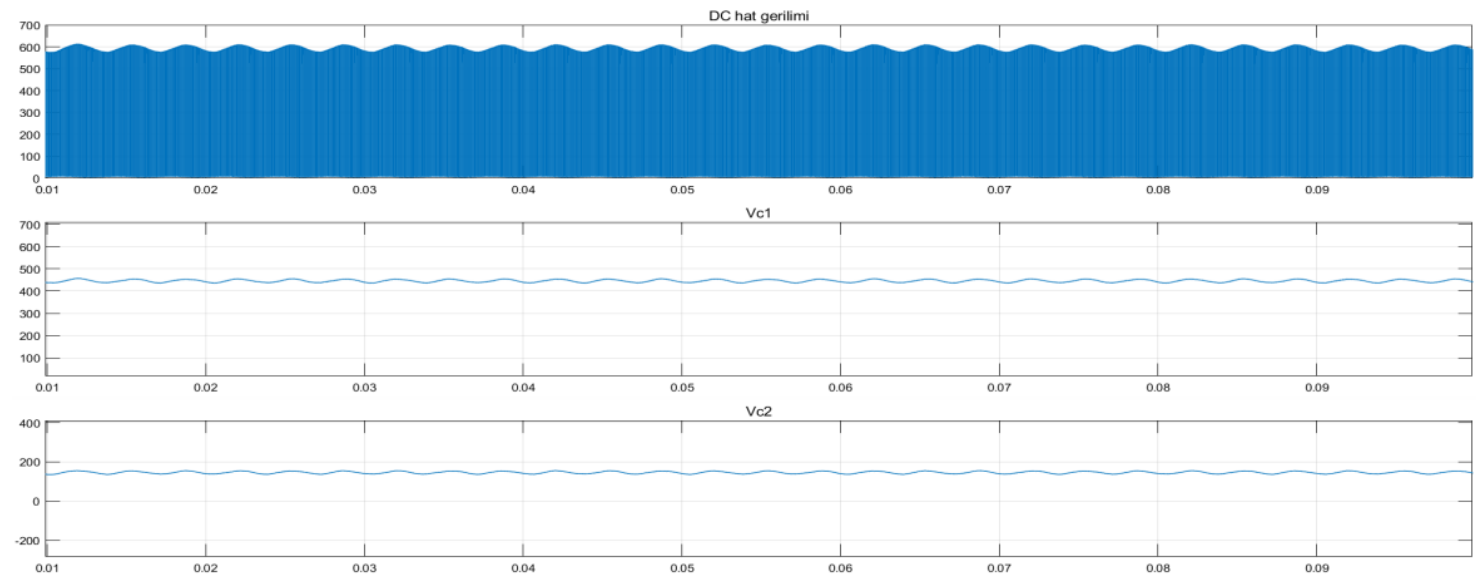

Şekil 10. Yükseltici modda $\mathrm{V}_{\mathrm{PN}}$ ve $\mathrm{V}_{\mathrm{C}}$ gerilimleri $(\mathrm{M}=0.82)$

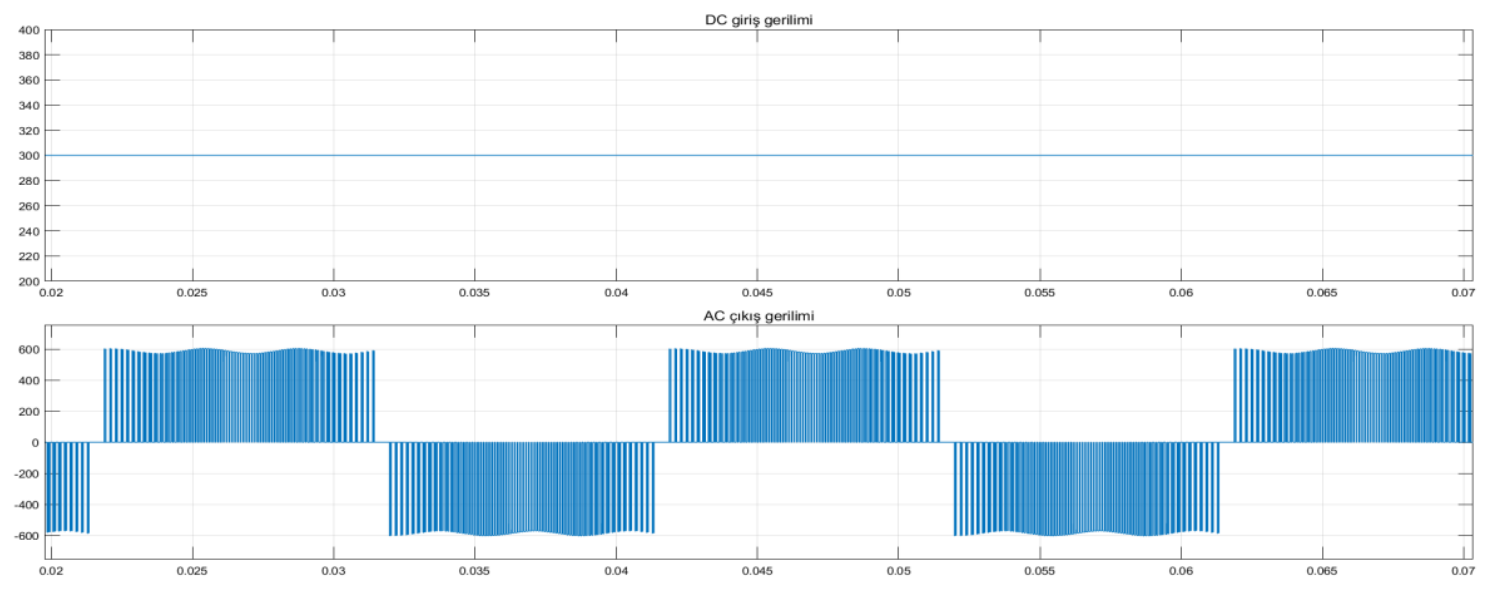

Şekil 11. Yükseltici modda $\mathrm{V}_{\mathrm{DC}}$ ve $\mathrm{V}_{\mathrm{AC}}$ gerilimleri $(\mathrm{M}=0.82)$

Elde edilen benzetim sonuçları karşılaştırıldığında, farklı çalışma koşulları altında qZSI devresinin hem düşürücü hem de yükseltici olarak kullanılabileceği açıkça görülmektedir. Geleneksel gerilim kaynaklı inverterler sadece düşürücü modda çalışabildiklerinden çıkışta istenilen gerilim seviyesini elde edebilmek için belirli bir değerin üzerinde DC giriş gerilim kaynağına ihtiyaç duyarlar.

Tablo 1'de verilen bulgulara göre, istenilen duruma bağlı olarak tek bir aşamada hem düşürücü hem de yükseltici olarak çalışabilen qZSI devresi, gerilim kaynaklı invertere kıyasla daha geniş bir gerilim aralığında çalışabilmesinden dolayı fotovoltaik sistemler için daha kullanışlıdır. BYK ve MYK yöntemlerine göre daha etkin ve kullanışlı olan MSYK yöntemiyle, sabit ve değişken olmayan kısa devre sinyalleri kullanılarak istenilen gerilim yükseltmesi sağlanmıştır.

Tablo 1. DC hata gerilimleri ve çıkış fazının tepe gerilimleri

\begin{tabular}{c|c|c}
\hline Çalışma Parametreleri & DC Hat Gerilimi & Çıkıs Fazının Tepe Gerilimi \\
\hline $\begin{array}{c}\mathrm{M}=1 \mathrm{~V}_{\mathrm{DC}}=600 \mathrm{~V} \\
\mathrm{~B}=1 \mathrm{G}=1\end{array}$ & $600 \mathrm{~V}$ & $300 \mathrm{~V}$ \\
\hline $\mathrm{M}=1 \mathrm{~V}_{\mathrm{DC}}=450 \mathrm{~V}$ & $612 \mathrm{~V}$ & $305 \mathrm{~V}$ \\
$\mathrm{~B}=1.37 \mathrm{G}=1.37$ & & \\
\hline $\mathrm{M}=0.82 \mathrm{~V}_{\mathrm{DC}}=300 \mathrm{~V}$ & $675 \mathrm{~V}$ & $300 \mathrm{~V}$ \\
$\mathrm{~B}=2.35 \mathrm{G}=1.95$ & & \\
\hline
\end{tabular}




\section{Sonuç}

Bu çalışmada; farklı modülasyon indeksleri ve DC giriş gerilim değerlerinde MSYK tekniği kullanılarak qZSI dönüştürücü devresinin çalışma performansı incelenmiştir. Öncelikle belirtilen durumlar için ilgili denklemler ile teorik analiz yapılmış, daha sonra Matlab/Simulink programı yardımıyla benzetim çalışmaları gerçekleştirilmiştir. Yapılan teorik analizler ile benzetim çalışmalarının uyumlu olduğu görülmüştür. qZSI inverter devresinin girişte bulunan güç kaynağından sabit akım çekebilme özelliği ve empedans katındaki düşük nominal değerli elemanlara sahip olması, ZSI inverter devresine göre daha avantajlı olmasını sağlamıştır. Geleneksel gerilim kaynaklı inverterlere kıyasla çalışma performansı açısından incelendiğinde qZSI inverter devresi, ihtiyaç duyulan durumlarda kısa devre çalışma özelliğini kullanarak tek bir aşamada hem yükseltme hem de dönüştürme sağlamış, kısa devre çalışma gerektirmeyen durumlarda normal gerilim kaynaklı bir inverter devresi gibi düşürücü modda sadece dönüştürücü olarak çalışmıştır. $\mathrm{Bu}$ şekilde qZSI devresinin geleneksel gerilim ve akım kaynaklı inverter devrelerine kıyasla çok daha geniş bir gerilim aralığında çalışabileceği gösterilmiştir. Bu nedenle qZSI devresi, giriş geriliminin sıcaklık ve 1şıma gibi çevre şartlarına bağlı olarak doğrudan etkilendiği fotovoltaik uygulamalarda yaygın olarak tercih edilmektedir. Kullanılan kontrol yöntemi ile sabit kısa devre çalışma oranı elde edilerek anahtarlama elemanları sürülmüştür. Elde edilen bulgular; DC gücün AC güce en yüksek verimlilikle dönüştürülmek istendiği güneş ve rüzgâr gibi yenilenebilir enerji sistemleriyle ilgili çalışma yürüten araştırmacılara fikir vermesi bağlamında faydalı olacaktır.

\section{Kaynakça}

Anderson, J., \& Peng, F. Z. (2008, June). Four quasi-Z-source inverters. In 2008 IEEE Power Electronics Specialists Conference (pp. 2743-2749). IEEE.

Battiston, A., Miliani, E. H., Pierfederici, S., \& Meibody-Tabar, F. (2016). Efficiency improvement of a quasi-Z-source inverter-fed permanent-magnet synchronous machine-based electric vehicle. IEEE Transactions on Transportation Electrification, 2(1), 14-23.

Ellabban, O., \& Abu-Rub, H. (2016). Z-source inverter: Topology improvements review. IEEE Industrial Electronics Magazine, 10(1), 6-24.

Endiz, M. S., Serafettin, E. R. E. L., \& Yagci, M. (2015). Comparative Study of Single Phase Power Inverters Based on Efficiency and Harmonic Analysis. i-Manager's Journal on Instrumentation \& Control Engineering, 4(1), 1-9.

Endiz, M. S., \& Akkaya, R. (2019). Comparative Analysis of Z-Source Inverter Control Techniques for Photovoltaic Applications. iManager's Journal on Power Systems Engineering, 7(2), 1-10.

Endiz, M. S., \& Akkaya, R. (2020) Yarı Empedans Kaynaklı İnverterlerde Farklı PWM Kontrol Tekniklerinin Performans Etkisinin İncelenmesi. Necmettin Erbakan Üniversitesi Fen ve Mühendislik Bilimleri Dergisi, 2(1), 12-26.

Endiz, M. S., \& Akkaya, R. (2020). A Modified Quasi-Z-Source Inverter with Enhanced Boost Capability. International Journal of Renewable Energy Research (IJRER), 10(2), 892-897.

Kabalc1, E. (2020). Review on novel single-phase grid-connected solar inverters: Circuits and control methods. Solar Energy, 198, $247-274$.

Liu, Y., Ge, B., Ferreira, F. J., de Almeida, A. T., \& Abu-Rub, H. (2011, October). Modeling and SVPWM control of quasi-Z-source inverter. In 11th International Conference on Electrical Power Quality and Utilisation (pp. 1-7). IEEE.

Liu, Y., Abu-Rub, H., \& Ge, B. (2014). Z-SourcelQuasi-Z-Source inverters: derived networks, modulations, controls, and emerging applications to photovoltaic conversion. IEEE Industrial Electronics Magazine, 8(4), 32-44.

Peng, F. Z. (2003). Z-Source Inverter. IEEE Transactions on Industry Applications, 39, 504-510.

Peng, F. Z., Shen, M., \& Qian, Z. (2005). Maximum boost control of the Z-source inverter. IEEE Transactions on power electronics, 20(4), 833-838.

Shen, M., Wang, J., Joseph, A., Peng, F. Z., Tolbert, L. M., \& Adams, D. J. (2004, October). Maximum constant boost control of the Z-source inverter. In Conference Record of the 2004 IEEE Industry Applications Conference, 2004. 39th IAS Annual Meeting. (Vol. 1). IEEE.

Subhani, N., Kannan, R., Mahmud, M. A., \& Romlie, M. F. (2019). Performance Analysis of a Modernized Z-Source Inverter for Robust Boost Control in Photovoltaic Power Conditioning Systems. Electronics, 8(2), 139.

Yu, Z., \& Sajadian, S. (2020, February). Trends on Predictive Control Schemes for Impedance Source Converters. In 2020 IEEE Power and Energy Conference at Illinois (PECI) (pp. 1-6). IEEE. 